Categoria

Trabalho Acadêmico\Resumo Expandido

Titulo do Trabalho

\title{
SAÚDE E EDUCAÇÃO: VALORIZANDO A VIDA SEM DROGAS
}

Nome do Autor (a) Principal

Jascqueson Alves de Oliveira

Nome (s) do Coautor (a) (s)

Charles Maciel Falcão

Nome (s) do Orientador (a) (s)

Instituição ou Empresa

Universidade Federal do Amazonas - UFAM

Instituição (s) de Fomento

Pró-reitoria de Extensão e Interiorização - PROEXTI

E-mail de contato

Jascqueson@oi.com.br

Palavras-chave

Drogas. Prevenção. Escola.

\section{INTRODUÇÃO}

A prevenção e o enfrentamento dos problemas relacionados ao uso indevido de drogas na infância e na adolescência é algo que requer um prévio conhecimento das informações acerca de todos os aspectos envolvidos no consumo de substâncias 
psicoativas, de modo a promover novas discussões e reflexões sobre os impactos na vida dos usuários do ponto de vista físico, psíquico e social.

\section{OBJETIVO GERAL}

Julgando a importância do tratamento da questão em seus diversos contextos, o presente projeto de extensão buscou discutir a necessidade de realização de momentos de reflexão sobre a temática do uso indevido de drogas, a partir do reconhecimento do espaço da escola como um importante agente de socialização capaz de contribuir para a prevenção e o enfrentamento da questão.

\section{OBJETIVOS ESPECÍFICO}

- Mostrar as diferenças dos tipos de drogas lícitas e ilícitas;

- Debater e refletir sobre a dependência das drogas;

- Realizar as formas de prevenção quanto ao uso das drogas;

- Apresentar os resultados dos trabalhos de prevenção às drogas.

\section{METODOLOGIA}

Atuando com os alunos e professores do Ensino Fundamental e Médio do turno vespertino da Escola Municipal Agenor Smith, localizada na estrada Coari Mamiá, município de Coari/AM, além das demais parcelas constituintes da comunidade escolar, o projeto oportunizou o conhecimento e a discussão reflexiva acerca da interdependência dos diversos contextos que atuam como fatores de risco ou de proteção ao uso indevido de drogas para que, num segundo momento, fosse possível criar estratégias que nos possibilitasse atuar com maior ênfase na prevenção e no enfrentamento da questão, tendo como ponto de partida o protagonismo dos jovens. Foram desenvolvidas palestras educativas e oficinas para a confecção de trabalhos junto aos alunos das diferentes turmas. 


\section{RESULTADO (S)}

A partir da dinâmica de realização do projeto em diferentes situações envolvendo o uso indevido de drogas foram apresentadas e discutidas com diferentes turmas de Ensino Fundamental e Médio da escola selecionada, foi possível perceber o entusiasmo dos alunos em conhecer as consequências que o uso de drogas pode causar no organismo humano e, a partir daí, assumir uma postura de enfrentamento do problema. O projeto foi encerrado com a realização de uma grande gincana durante a qual os estudantes colocaram em prática os ensinamentos repassados com a produção de cartazes, frases, poesias e desenhos produzidos durante o desenvolvimento do projeto.

\section{CONSIDERAÇÕES FINAIS}

Acreditamos que as famílias, as escolas e outras instituições que agregam crianças, jovens e adolescentes onde são desenvolvidas relações socioambientais, dependendo de sua importância no contexto social, podem contribuir de maneira significativa na sensibilização das pessoas em relação ao uso indevido de drogas. Isto de certa forma depende da concepção que temos sobre o tipo de sociedade que queremos ter.

\section{REFERÊNCIAS}

BRASIL. Lei № 8.069, de 13 de julho de 1990 (Estatuto da Criança e do Adolescente). Senado Federal, Brasília, 2007.

CORRADI-WEBSTER, C. M.; ESPER, L. H.; PILLON, S. C. A enfermagem e a prevenção do uso indevido de drogas entre adolescentes. Acta Paulista de Enfermagem, 2009;22(3)331-4.

FORJAZ, S. S. Acorda! Que a corda é bamba. São Paulo: Aquariana, 2005.

MOURA, Y. G.; SILVA, E. A.; NOTO, A. R. Redes sociais no contexto de uso de drogas entre crianças e adolescentes em situação de rua. Psicologia em pesquisa UFJF, 3(1): 31-46, janeirojunho, 2009.

SCHENKER, Miriam; MINAYO, Maria Cecília de Souza. Fatores de risco e de proteção para o uso de drogas na adolescência. Ciência \& Saúde Coletiva [online]. 2005, vol.10, n.3, pp. 707717. ISSN 1413-8123. Disponível em: <www.scielo.br> Acesso em: 17 dez. 2009. 